\title{
INDUSTRY SEGMENTATION UNDER ENVIRONMENTAL PRESSURE: AN OPTIMAL APPROACH
}

\author{
Feng DAI, Jingxu LIU, Ling LIANG \\ Department of Management Science, Zhengzhou Information Engineering University, \\ Building 75-1-701, No. 5, Jian-Xue Street, Wen-Hua Road, Zhengzhou, 450002 Henan, China
}

Received 24 November 2012; accepted 02 November 2013

\begin{abstract}
Based on the Solow growth model, this paper builds a combinatorial model for economic growth under environmental pressure. Using the model, the optimal number of industries in an economy can be computed, and the "optimal number" can be regarded as a criterion for decision making concerning industry segmentation. This paper presents a critical value of the number of industries in an economy, which determines the economic output to grow (or not) after industry segmentation. The findings include the following: (1) technological progress and innovative growth cause an industry segmentation, and (2) industry segmentation is the primary approach to sustaining economic growth under environmental pressure.
\end{abstract}

Keywords: economic growth, environmental pressure, industry segmentation, optimal structure, competitive relation.

Reference to this paper should be made as follows: Dai, F.; Liu, J.; Liang, L. 2013. Industry segmentation under environmental pressure: an optimal approach, Technological and Economic Development of Economy 19(Supplement 1): S524-S543.

JEL Classification: E17, L16, O44.

\section{Introduction}

Industry segmentation is a process in which production and operation are subdivided according to different fields. Industrial segmentation is based on industrial specialization and market segmentation, which are used to meet the demands of economic growth. With the increase in new technologies and innovations, market and industrial segmentation has become increasingly important and common in economic development, which poses problems that deeply concern economists.

Corresponding author Feng Dai

E-mail:fengdai@126.com 
Studies on market and industry segmentation include the following. Pupillo and Zimmermann (1991) contribute to the emerging field of international trade and industrial organization, and their work indicates that markets are segmented. Mitchell and McDade (1992) reconsider the market segmentation theory by focusing on property and liability insurance companies and find strong evidence of market segmentation. Allen and Jagtiani (1997) differentiate between depository institutions, insurance companies, mutual funds, and other financial firms and find evidence of market segmentation in both market risk levels and market risk premiums. Shapiro and Shi (2008) investigate the role of discount travel agencies, such as Priceline and Hotwire, in the market segmentation of the hotel and airline industries and find support for an inverse relationship between the quantity and price for market risk. Liu et al. (2010) discuss the multi-criterion nature of market segmentation and develops a new mathematical model that addresses this issue. Menzly and Ozbas (2010) present evidence supporting the hypothesis that due to investor specialization and market segmentation, value-relevant information diffuses gradually in financial markets. Kesting and Rennhak (2011) highlight the general procedures as well as the challenges arising from the context of developing and implementing market segmentation concepts and find that segmentation activities may differ considerably depending on factors such as sector, industry, and company size. Their field study also identifies some remarkable trans-sectoral similarities concerning segmentation issues. Ruiz de Ma et al. (2011) analyse the market for organic products in eight European countries and identify international segments in the European organic products market. These works show that the segmentation exists in almost every economic market and industry. On the other hand, $\mathrm{Mu}$ and Lee (2005) discuss market segmentation and technological catch-up based on the case of the telecommunications industry in China. Gluschenko (2010) analyses the role of various market frictions in inducing the segmentation of the Russian goods market and finds that the spatial disconnectedness of regions is responsible for approximately 70 percent of the average price differential. Hoffmann and Soyez (2010) find that, to optimize marketing campaigns, practitioners need to know the characteristics of this key segment in the diffusion process and suggest a theoretically founded cognitive model of domain-specific innovativeness for a product category with a utilitarian benefit. Zhang and $\mathrm{Wu}$ (2012) identify market segments and estimate the residents' willingness to pay for green electricity in China. Their findings reveal that the segmentation is caused by the significant differences in demographic variables, such as level of education, household income, and location of residence, across the population segments. These studies have discussed the various causes and manners of market segmentation.

Industrial segmentation is different from market segmentation, although the former is caused by the latter. Studies on industrial segmentation are quite important, especially those incorporating environmental pressure. In fact, any national government or authority may have to face the following problem when making economic decisions.

What the current research does not address, however, is (1) how to determine the optimal number of leading industries for a given economy, (2) how the optimal number changes and what we can conclude about that optimal number, and (3) the relationship between the number of industries and competition. 
This paper attempts to address these issues by presenting a combinatorial growth model under environmental pressure, studying the problem of industrial segmentation, and positing a method to compute the optimal number of leading industries in an economy. The computed results should be regarded as the number standard for leading industries in a given economy. In addition, this paper will draw the following important conclusions:

- The optimal number of leading industries in an economy increases with technological progress and innovative growth;

- Industry segmentation will increase economic output under environmental pressure;

- The optimal number of leading industries is negatively correlated with market competition.

\section{Foundation}

\subsection{Categorized production function}

Industries can generally be divided into two categories: traditional and emerging. Traditional industries are those that mostly involve labor and basic manufacturing, while emerging industries are those that mostly involve new science and technology. Traditional industries require large quantities of labor and equipment - resources that constitute the foundation of traditional industry. In a traditional industry, capital often takes a material form (e.g. equipment or buildings), while labor involves the efforts of workers with standardized skills. Technological progress is measured by the technologies embodied in capital equipment, final goods and services. Traditional industries usually employ advanced processing techniques and complete equipment systems and enjoy stable product markets. Traditional industries often require a higher cost of capital and better technology. In addition, technology levels in traditional industries tend to remain stable for long periods of time. In contrast, powerful technology is fundamental to emerging industries. In an emerging industry, capital may take a material or immaterial form; it may include equipment, patents, software, intangible assets and workers with standardized professional skills. Technology develops rapidly in emerging industries; thus, overall technological levels tend to evolve quickly.

For the sake of convenience, capital inputs will be expressed as the value of capital required in production, labor inputs as the number of workers required in production and technology inputs as the cost of research and development. Thus, the production function (Solow 1956, 1957; Barro, Sala-i-Martin 1995) for an economy can be expressed as $Y=A \cdot F(K, L)$, where $Y$ is real economic output, $K$ is capital, $L$ is labor, and $A$ is multifactor productivity. For given quantities of capital and labor, improvements in technology will yield increased output. Thus, economies with more advanced technology exhibit greater productive efficiency.

Because capital, labor and technology change over time $(K=K(t), L=L(t), A=A(t))$, the technology level $A(t)$, assuming differentiability, can also be expressed as $\frac{d A(t)}{d t}=h(t)$; thus, $A(t)=\int h(t) d t=H(t)+a$, where $a$ is a constant. Therefore, output can be expressed as:

$$
Y=Y_{1}+Y_{2}
$$

where: $Y_{1}=a \cdot F[K(t), L(t)]$ and $Y_{2}=H(t) \cdot F[K(t), L(t)]$. In Model (1), the technology level associated with output $Y_{1}=a \cdot F[K(t), L(t)], a$, is a constant, signifying a stable technology level, 
which is a characteristic of traditional industries. Therefore, $Y_{1}$, the output of traditional industries, is referred to as basic output. The technology level associated with output $Y_{2}=H(t) \cdot F[K(t), L(t)], H(t)$, is a function of time, signifying that the level of technology is variable, which is a feature of emerging industries. Therefore, $Y_{2}$, the output of emerging industries, is referred to as emerging output. Model (1) is referred to as the categorized production function (CPF) for traditional and emerging industries, where $A(t)=H(t)+a$ is categorized total factor productivity. Model (1) indicates that traditional industries have two inputs, capital and labor, whereas emerging industries have three inputs, capital, labor and technology. Model (1) can be concisely expressed as:

$$
Y=\mu+\sigma
$$

where: $\mu=a \cdot F[K(t), L(t)]$ is the production function for traditional industries; $\sigma=\mu \cdot q(t)$ is the production function for emerging industries; and $q(t)=\frac{H(t)}{a}$ is the ratio of the technology level of emerging industries to that of traditional industries, indicating the degree of technological progress and innovation, or innovation efficiency, of the former. Innovation efficiency is a dimensionless quantity that expresses the advantage in productive efficiency of emerging over traditional industries, and simply as innovation. Here, innovation encompasses all of the benefits of technological and scientific progress.

In general, traditional and emerging industries have different capital and labor requirements. Model (1), however, shows that the input factors of both traditional and emerging industries stem from the economy's overall quantities of capital and labor. This finding can be explained as follows. Each unit of capital can be divided into two parts: one part used in traditional industries and the other used in emerging industries. Similarly, each unit of labor can be divided into two skill types: one applicable to traditional industries and the other applicable to emerging industries. Thus, capital and labor can flow between traditional and emerging industries. When productive efficiency increases in emerging industries, capital and labor will flow toward those industries.

Model (1) illustrates that, for the economy as a whole, part of total output is produced by traditional industries, and the remainder is produced by emerging industries. If emerging industries are low in innovation efficiency, economic output mainly comes from traditional industries. If emerging industries are relatively high in innovation efficiency, economic output mainly comes from emerging industries. During periods of the latter type, the economy will likely be highly developed, because growth is largely driven by innovation.

\subsection{An economic growth model including environmental pressure}

Economic growth requires productive inputs and consumes a variety of economic resources. However, it is important to note that economic growth can be hindered by various factors, including resource scarcity, market competition, investment risk, financial risk, environmental crises, social unrest, natural disasters, disease, and war, all of which generate environmental pressure (or resistance) to economic growth. It is also worth noting that, in addition to promoting economic growth, innovation may itself generate environmental pressure; it may increase resource consumption, environmental pollution, or investment risk, which increase 
the consumption of real output and thus raise innovation costs. The consumption of social and economic resources due to environmental pressure generated by economic growth is referred to as exogenous cost.

The exogenous cost of basic output is denoted as $\phi$ and the exogenous cost of emerging output as $\kappa$. Exogenous costs arise from environmental pressure related to factor inputs. When factor inputs change, exogenous costs also change. According to Reed (2001) and Schoenberg et al. (2003), the ratio of the change in exogenous costs to the change in factor inputs is a power function of current inputs; that is:

$$
\frac{d \phi}{d \mu}=v \mu^{\varphi} \text { and } \frac{d \kappa}{d \sigma}=w \sigma^{\varphi},
$$

where: $\varphi>0$ indicates the existence of environmental pressure; and $v$ and $w$ are the exogenous cost coefficients for basic and emerging output, respectively, expressed simply as basic and emerging cost coefficients. Hence, the basic and emerging exogenous costs are:

$$
\phi=\frac{v}{\theta} \mu^{\theta} \text { and } \kappa=\frac{w}{\theta} \sigma^{\theta},
$$

respectively, where $\theta=\varphi+1$ is called the environmental pressure index (EPI). Without loss of generality, let the constants of integration equal zero. Because the capital rental rate and labor wage rate are inevitably impacted by the economic environment, the costs of capital and labor can be regarded as parts of the exogenous cost.

Following Sanchez et al. (2007), we assume that the authority can adjust EPI through economic policy. Specifically, it can reduce EPI through free and open (free-market and non-protectionist) policy and increase EPI through a closed and protective policy, but it cannot eliminate environmental pressure altogether, that is, $\theta>1$. The formulas for exogenous costs indicate that an increase in productive inputs will be accompanied by an increase in environmental pressure or exogenous cost. Generally, the environment for sustained growth is likely to improve gradually. However, in achieving long-term growth and development, an economy faces a growing number of challenges of increasing complexity, challenges (arising from such issues as institutional policy, financial risk, environmental crisis, social unrest, natural disaster, disease, and war) that will be increasingly difficult to address under current approaches. Indeed, traditional and emerging industries may face different environmental pressures, and governments may accordingly implement different policies to address development and growth in the case of each industry type. For convenience, however, we assume equality between the environmental pressure indices for traditional and emerging industries ${ }^{1}$.

Given that economic growth cannot be neatly separated from environmental pressure and resulting exogenous costs, the real output based on Model (1) can be expressed as:

$$
y=\mu+\sigma-(\phi+\kappa)=\mu \cdot G,
$$

where $G=1+q-\frac{1}{\theta}\left(v+w q^{\theta}\right) \mu^{\theta-1}$ is the total factor productivity with environmental pressure and EPI can be expressed as $\theta=\frac{d \kappa}{\kappa} / \frac{d \sigma}{\sigma}$. Model (2), which can be referred to as a normal

\footnotetext{
For convenience, we assume equality between the environmental pressure indices for traditional and emerging industries. In general, the environmental pressure index for traditional industry may be different from that for emerging industry. In the case, the exposition is similar to current one, but will be more complex.
} 
growth model with environmental pressure, is also an advance-retreat course (ARC) model (Dai et al. 2011, 2013). According to the Cobb-Douglas production function, basic output can be expressed as $\mu=a \cdot F[K(t), L(t)]=\mu_{0} K^{\alpha} L^{\beta}$ in $\operatorname{Model}(2)$, where $K$ and $L$ represent capital and labor, respectively; $\mu_{0}=a \cdot c_{0}, c_{0}$ are initial values; and $\alpha, \beta>0$. The emerging industry output can then be expressed as $\sigma=\sigma_{0} K^{\alpha} L^{\beta} q$. Because the capital rental rate and labor wage rate will inevitably be affected by the economic environment, the costs of capital and labor can be regarded as part of the exogenous costs. Model (2) is simplified to the Solow growth model (Solow 1957) if $v=w=0$, and to the Cobb-Douglas production function if $v=w=0$ and $\sigma_{0}=0$. On the other hand, if $\theta=1$ and $v \neq 0$ and $w \neq 0$, the environmental costs are linear, and thus $y=(1-v) \mu+(1-w) \sigma$, which can be discussed according to works on the Solow model.

Model (2) indicates that during normal economic growth, environmental pressure increases as output increases, which continues until the economy goes into recession. Only successful policies and institutional reform can generate a new economic environment, relieve the existing environmental pressure, and initiate a new cycle of economic growth. As the economy continues to grow, however, additional environmental pressure accrues. Hence, the ARC model (2) reflects the cyclical features of economic growth.

\section{Model}

\subsection{Notation}

Suppose an economy includes $m$ economic entities, $m>1$. If the economy is a national economy, the entities correspond to the leading industries. For the economy and the entity $i(i=1, \cdots, m)$, the notations that will be used are as follows:

$\Gamma$ - basic output of the economy, $\Gamma>0$;

$U$ - emerging output of the economy, $U>0$;

$\mathrm{F}$ - basic exogenous cost of the economy, $\mathrm{F} \geq 0$;

$K$ - emerging exogenous cost of the economy, $K>0$;

$Y$ - real output of the economy;

$\mu_{i}$ - basic output of the entity $i, \mu_{i}>0$;

$\sigma_{i}$ - emerging output of the entity $i, \sigma_{i}>0$;

$\phi_{i}$ - basic exogenous cost of the entity $i, \phi_{i} \geq 0$;

$\kappa_{i}$ - emerging exogenous cost of the entity $i, \kappa_{i}>0$;

$Y_{i}-$ real output of the entity $i$.

\subsection{Integrated emerging output and exogenous cost}

Generally, the emerging output of an economy is the sum of all emerging outputs of its entities; that is:

$$
U=\sum_{i=1}^{m} \sigma_{i}
$$


There may be a clear boundary between the traditional industries such that the technologies and innovations in an industry are not well suited to other industries. For example, agricultural technologies are not usually suitable for industrial production. Thus, each exogenous cost of traditional industries can be regarded as independent of one another; thus, the basic exogenous cost of economy is the sum of all basic exogenous costs of industries. There is usually a high correlation between emerging outputs; that is, technologies and innovations are significantly correlated across the emerging outputs. For example, computer and chip technology have been used in modern industrial control, weather analysis, aerospace engineering, communication engineering, and many other fields. Similarly, modern textile industries, paper industries, steel industries, and mechanical and electrical industries are inseparable from control technologies and innovations. Meanwhile, there is intense and extensive competition among emerging outputs in terms of workers, capital, technologies, products, and market. Therefore, the influence of environmental pressure on emerging outputs is correlated, which means that the emerging exogenous cost of an economy is different from the basic exogenous cost in structure; in other words, emerging exogenous costs are correlated. Thus, the growth rate of the emerging exogenous costs of an economy is comprised of those of its entities in linear way:

$$
\frac{d K}{K}=\beta_{1} \frac{d \kappa_{1}}{\kappa_{1}}+\cdots+\beta_{m} \frac{d \kappa_{m}{ }^{2}}{\kappa_{m}},
$$

where: $\beta_{i}$ represents the competitive status of entity $i$ in the economy, referred to as competitive advantage, $\beta_{i}>0$. The competitive structure of the economy can be described by the relationship between $\beta_{1}, \cdots, \beta_{m}$. The larger the competitive advantage $\beta_{i}$, the higher the pressure caused by entity $i$ on other entities.

According to the expression of emerging exogenous cost, i.e. $\kappa=\frac{w}{\theta} \sigma^{\theta}$, the EPI of an economy can be expressed as $\theta=\frac{d K}{K} / \frac{d U}{U}$ and those of entities as $\theta_{i}=\frac{d \kappa_{i}}{\kappa_{i}} / \frac{d \sigma_{i}}{\sigma_{i}}$. Therefore, we have $\frac{d K}{K}=\theta \frac{d U}{U}=\beta_{1} \theta_{1} \frac{d \sigma_{1}}{\sigma_{1}}+\cdots+\beta_{m} \theta_{m} \frac{d \sigma_{m}}{\sigma_{m}}$. The emerging exogenous cost of an economy is then as follows:

$$
K=\frac{w}{\theta} U^{\theta}=K_{0} \sigma_{1}^{\beta_{1} \theta_{1}} \cdots \sigma_{m}^{\beta_{m} \theta_{m}} .
$$

Denoting $\rho_{i}=\frac{d \sigma_{i}}{\sigma_{i}} / \frac{d U}{U}$, the EPI of an economy can be expressed as follows:

$$
\theta=\sum_{i=1}^{m} \beta_{i} \rho_{i} \theta_{i}
$$

where: $\alpha_{i}$ is referred to as the emerging output elasticity of entity $i$ related to economy, which indicates how the emerging output growth rate of the entity impacts the EPI of an economy.

The linear relationship between the growth rates of the emerging exogenous costs may clearly and succinctly describe the integration of environmental pressures, and the all-round competition between industries in capital, manpower and technique. The later empirical analysis will indicate that the assumption is appropriate. Of course, other relationships between environmental pressures on the industries in an economy can be taken into account if needed. 


\subsection{The combinatorial ARC model of an economy}

Following Model (2) and Equations (3), (4), and (5), the real output of an economy including $m$ industries under environmental pressure is as follows:

$$
Y=\Gamma+U-(\Phi+K)
$$

where: $\Gamma=\sum_{i=1}^{m} \mu_{i}, \quad \Phi=\frac{v}{\theta} \Gamma^{\theta}=\sum_{i=1}^{m} \phi_{i} ; \quad U=\sum_{i=1}^{m} \sigma_{i} ; \quad K=\frac{w}{\theta} U^{\theta}=K_{0} \sigma_{1}^{\beta_{1} \theta_{1}} \cdots \sigma_{m}^{\beta_{m} \theta_{m}} ;$ and $U=\Gamma \cdot Q$, where $Q$ represents the innovation. Model (6) is referred to as the combinatorial ARC model.

\subsection{Types of competition}

Resources (for example, for raw materials, capital, product market, and people with a particular technical ability) exist in an economy, and there is competition among the same type of entities in the economy, which may be complete or incomplete. The competitive relationships among different entities can be described by the competitive advantage $\beta_{i}$ in Equation (5), and these advantages can be placed in the following four classifications:

- Mutual benefit. When $0<\sum_{i=1}^{m} \beta_{i}<1$, there is a mutually beneficial relationship among the entities. When $\theta<\rho_{i_{0}} \theta_{i_{0}}=\max _{1<i<m}\left\{\rho_{i} \theta_{i}\right\}$ and $\frac{\dot{K}}{K}<\frac{\dot{\kappa}_{i_{0}}}{\kappa_{i_{0}}}$, the environmental pressure on the economy is less than that of any given entity. Therefore, there exists a mutually beneficial relationship that allows the entities to develop together;

- Non-competition. When $\sum_{i=1}^{m} \beta_{i}=1$, there is a non-competitive relationship among the entities. In this case, the growth rate of environmental pressure on an economy is equal to the arithmetic average of the growth rates of environmental pressure on the entities. Therefore, there is no competition among entities, and there is no mutually beneficial relationship;

- Incomplete competition. When $1<\sum_{i=1}^{m} \beta_{i}<m$, there is an incomplete competitive relationship among the entities. In this case, the growth rate of environmental pressure on an economy is larger than the arithmetic average of the growth rates of environmental pressures on the entities but less than their simple sum. This implies that there is competition among entities to some degree, which is incomplete competition. The incompleteness of the competition is proportional to the change in values of $\sum_{i=1}^{m} \beta_{i}$;

- Complete competition. When $\sum_{i=1}^{m} \beta_{i} \geq m$, there is a complete competitive relationship among the entities. In this case, the growth rate of environmental pressure on an economy is equal to or greater than the simple sum of the growth rates of those entities. The competition among the entities in this case is an intense, life-or-death situation. In particular, if $\beta_{i}=1$, the competition is called standard complete competition. 


\section{Results and discussion}

\subsection{Results}

If there are $m(>1)$ leading industries in an economy and they are all equivalent (with "equivalent" meaning that the importance, output, and market risk of the industries are similar but their products and raw materials are different, i.e. the industries are competing with one another, which includes incomplete competition for capital, labor, and energy, but they are not competing for customers and market). Then, we suppose that, (1) the emerging output growth rates of industries are all equal to that of the economy, i.e. $\rho_{i}=\frac{d \sigma_{i}}{\sigma_{i}} / \frac{d U}{U}=1 ;(2)$ the competitive advantages of industries are equal to each other, i.e. $\beta_{i}=\beta$; and (3) the EPIs of the industries are equal to each other, i.e. $\theta_{i}=\psi$. According to Equation (5) and Model (6), the ARC model of each leading industry can be expressed as:

$$
Y_{m}=\frac{\Gamma-\Phi}{m}+\frac{U}{m}-\left(\frac{w}{\theta} U^{\theta}\right)^{\frac{1}{m \beta}} \text {. }
$$

where: $\theta=m \beta \psi$.

According to Appendix A, the optimal number of leading industries in an economy is as follows:

$$
m^{*}=\frac{1}{\beta} \ln \left(\frac{w}{\theta} U^{\theta}\right)
$$

where: $U \geq\left(\frac{\theta}{w} e^{\beta}\right)^{1 / \theta}$. Then, the real maximum output after industry segmentation is as below:

$$
Y^{*}=m^{*} \cdot Y_{m^{*}}=\Gamma-\Phi+U-\frac{e}{\beta} \ln \left(\frac{w}{\theta} U^{\theta}\right) .
$$

From Equation (8), the optimal number of leading industries in an economy depends on competitive advantage, EPI, and emerging output. The optimal number of leading industries decreases as the competitive advantage increases and increases as the emerging output increases. We see, from Appendix A, that the real economic output (9) reaches its maximum when the number of industries follows Equation (8). That means that the economic structure is optimal in the number of industries, and we call the economy has an optimal structure. If economy has always an optimal structure, the real economic output will maintain its maximum and economy will keep developing in an optimal approach.

From Appendix A and Equation (8), Conclusion 1 is obtained below.

Conclusion 1. There is an optimal number of leading industries in an economy. If the current number of leading industries in an economy is equal to the optimal number, then the real output of the economy achieves its maximum value. If the emerging output of the economy grows, that is, the innovation in the economy increases, the optimal number of leading industries will also increase.

Conclusion 1 states that economy is always pursuing a high-efficiency state, which leads to an increase in the number of leading industries with technological progress and innovative growth because the increase in the number of leading industries promotes industrial spe- 
cialization, the utilization of various resources, and a decrease in the environmental pressure in industrial growth. The optimal number of leading industries in an economy increases, which means that leading industries are always subdivided in their development. Therefore, industrial segmentation is an inevitable result of technological progress and innovative growth. We are able to determine the optimal number of leading industries at any point of segmentation, which is a valuable tool for controlling the rhythm of economic development.

From Appendix B and Equation (B.2), Conclusion 2 is obtained as follows.

Conclusion 2. There is a critical value for industry segmentation. If the real number of leading industries is larger than the critical value, then industry segmentation will increase the real output of the economy. In this case, the more leading industries there are, the higher the real output of the economy.

Conclusion 2 states that the government and other authorities need to reasonably promote industrial segmentation, which can effectively promote the stable and sustainable economic growth. According to the critical value, the government and other authorities are able to reasonably control the number of industries.

From Conclusion 1 and Conclusion 2, Conclusion 3 is derived is as follows.

Conclusion 3 Technological progress and innovative growth will increase the optimal number of leading industries and thereby promote economic growth.

Industry and market segmentation is the most effective method for reducing the environmental pressure on economic growth and changing economic structure, as they can:

- Tap the potential for economic growth and market development. Industry and market segmentation can effectively discover the "blind zone" of growth and market demand, open up a new field of industrial growth, meet the needs of increasing consumption, and promote both employment and economic growth. Here, a "blind zone" is a market field that has not been previously identified but does include consumption demand, which will promote industrial growth;

- Avoid increasing economic and financial risk. Because industry and market segmentation will create a greater number of industries and markets, it will also decrease resource consumption and competition between those industries and markets. As a result, these industries can continue growing even if other industries are in crisis;

- Manage industries in a more standardized and specialized way. Because industry and market segmentation can produce a more ideal product and demand configuration in an economy, the economy is more likely to fully utilize specialized production and management technology, thus achieving highly efficient classed tax and financial management.

\subsection{Discussion}

In addition to the works introduced in the introduction, there are many other revelant studies:

- Battisti and Pietrobelli (2000) develop a theoretical framework to analyse intra-industry gaps in technology and explain the existence of inter-firm technological gaps by factor market segmentation. Corrocher and Zirulia (2010) argue that in a context of uncertainty, demand affects firms' innovative strategies by increasing the capa- 
bility of market segmentation and by providing the incentives to innovate. Boffa and Panzar (2012) propose a regulatory mechanism for vertically related industries in which the upstream bottleneck segment faces significant returns to scale while other (downstream) segments may be more competitive. Choi (2013) constructs a simple asset market segmentation model to study the relationship between inflation and theft when money is the only medium of exchange;

- Degryse and Ongena (2004) believe that increased interbank activity results in the development of either transactional banking or bank industry specialization. Clark (2006) finds that industries that are engaged in vertical specialization-based trade make production location decisions that cause the specialization of industrial development. Using measures of diversification based on the diversity in segment-industry characteristics, $\mathrm{He}$ (2009) documents a diversification premium in the post-1997 period and determines significant positive effects of cash flow diversity, leverage diversity, and profitability diversity on excess value. Brandt and Thun (2011) examine how a shift in the end point of a global value chain alters the prospects for industrial upgrading in a developing economy through an analysis of the mobile telecom sector in China and find that domestic Chinese firms have been able to take advantage of both increasing modularity and their superior knowledge of low-end market segments to expand sales vis-a-vis foreign firms;

- Chen and Bell (2012) examine how a firm that faces customer returns can enhance profit by using different customer returns policies as a device to segment its market into a dual-channel structure. Ko et al. (2012) note that researchers have paid relatively little attention to whether markets can be segmented cross-nationally, and their findings support the existence of similarities across global fashion markets that allow the sportswear industry to target market segments based on the theoretical framework.

Differing from the above studies, Models (6) and (7) integrate traditional and emerging outputs, technological progress and innovation, and economic and environmental policy. Equation (8) provides a way to determine the optimal number of leading industries in an economy and how technological progress and innovative growth promote industry segmentation and economic growth. Equation (9) presents the real output for the optimal number of leading industries in a given economy. We can measure the competitive relations between industries in a given economy by the competitive advantages, which differs from the Boone indicator (Leuvenstei et al. 2011) and many well-known measures of competition. According to Conclusions 1, 2, and 3 above, as the number of leading industries increases, the following occurs:

1) Industry segmentation is the inevitable outcome of technological progress and innovation. Over time, technological progress and innovation become more specialized and precise. As a demand for economic growth, economic technological progress and innovation will promote the subdivision of the industry in more specialized and distinctive ways;

2) Industrial segmentation improves the efficiency of economic development. Industrial segmentation will also make the subdivided industries increasingly specialized and distinct from one another, which will result in improved standards management. This 
improvement increases the efficiency and decreases the cost of industrial development, which pushes industries to develop at a higher level;

3) Industrial segmentation improves resource integration and utilization. Industrial segmentation will make the resources in an industry more similar, which improves integration and efficiency regarding the utilization of resources, such as raw materials, throughput, professional labor, capital, and energy, among other things. Resource integration also encourages the development of specialized markets and industries and results in the utilization of the particular resources in a full way;

4) Industrial segmentation promotes product and market diversification. Because an economy always features multiple levels of production and various consumption demands, economic diversification is indispensable. Industrial segmentation can ensure that commodity diversification and multiple levels of production will occur;

5) An economic boom follows industrial segmentation. After the industries are fully subdivided in an economy, an increasing number of new special technologies and products will emerge to meet the diverse demands of society and consumption, leading to an economic boom.

\section{Empirical research}

\subsection{Using Model (6) to fit the U.S. GDP}

To prove the rationality of Model (6) and support all the results in the paper, Model (6) is used to fit the U.S. GDP below using the fitting function Fit $[\boldsymbol{Y}(\boldsymbol{t}), \boldsymbol{D}(\boldsymbol{t}), \boldsymbol{t}]$ in the MAPLE software system. The real GDP data ${ }^{3}$ used in this study were recorded as $D(t), t=1940, \cdots, 2010$.

Without the loss of generality, in Model (6), let $\Gamma=\Gamma_{0} e^{\lambda t}, U=U_{0} e^{(\lambda+s) t}, Q=Q_{0} e^{s t}$, and $U=\Gamma \cdot Q$. where $\lambda$ is the basic output growth rate of the economy, $s$ is the growth rate of innovation; the basic output growth rate $\lambda=0.110^{4}$ and economic innovation growth rate $s=0.097^{5}$. Model (6) is expressed as $Y_{\theta}(t)=\Gamma_{0} e^{0.11 t}+U_{0} e^{0.207 t}-\left(\Phi_{0} e^{0.11 \theta t}+K_{0} e^{0.207 \theta t}\right)$, which can be estimated by the regression method.

When the error is small and the coefficient of determination is large, the fitting result based on $\min _{\theta>1} \sum_{i=1940}^{2010}\left[Y_{\theta}(i)-D(i)\right]^{2}$ is:

$$
\begin{gathered}
\Gamma_{0}=54.9999328065753802 ; U_{0}=0.0941253361396964111 ; Q_{0}=0.00155316579 ; \\
\Phi_{0}=4.6794780639362 ; K_{0}=0.000058697096308285 ; \theta=1.412 .
\end{gathered}
$$

Data source: the United States White House website, http://www.whitehouse.gov.

4 Direct capital average growth rate (1940-2010) is 6.7\%, data source: U. S. White House Web, http://www.whitehouse. gov. Average growth rate of employment labor force (1940-2010) is 4.3\%, data source: U.S. Bureau of Labor Statistics Web, http://data.bls.gov/pdq/SurveyOutputServlet.

5 The growth rate of utility patent applications in U.S (1969-2010), data source: U.S. Patent and Trademark Office Web, http://www.uspto.gov/web/offices. 
absolute error: $\varepsilon_{1}=\sqrt{\sum_{t=1940}^{2010}[D(t)-\hat{Y}(t)]^{2} /(2010-1940)}=130.44133$; coefficient of determination $R^{2}=0.9934295912$. And:

relative error: $\varepsilon_{2}=(1 / \bar{D}) \cdot \sqrt{\sum_{t=1940}^{2010}[D(t)-\hat{Y}(t)]^{2} /(2010-1940)}=0.03341847114$;

$$
\bar{D}=\sum_{t=1940}^{2010} D(t) /(2010-1940) .
$$

where: $\hat{Y}(t)$ is the $Y_{\theta}(t)$ - based estimated function of U.S. GDP.

The GDP data and Model (6)-based U.S. GDP fitting curves are depicted in Fig. 1.

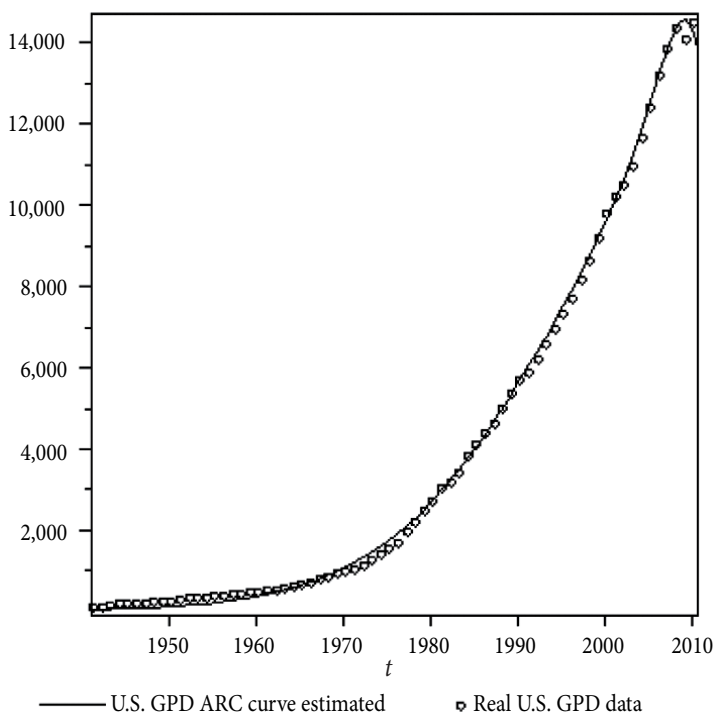

Fig. 1. U.S. GDP and ARC fitting (1940-2010)

Note: The units are in billions of U.S. dollars. The U.S. GDP data curves for the period 1940-2010 are illustrated. It can be observed that Model (6) its the GDP much better.

Fig. 1 indicates that Model (6) fits the U.S. GDP data well. The estimated U.S. GDP ARC curve reaches its Top Time at $T=2009.266529$, which means that the U.S. economy peaked and showed signs of decline near 2009 and that the tendency to decline continued after 2010. If there is a recovery in the U.S. economy and no effective reform policy is implemented, the recovery may be a weak one. In fact, if the current time is larger than the Top Time and no economic reform is carried out to the reduce EPI, then the real output (or GDP) will quickly decline and an economic crash will occur. 


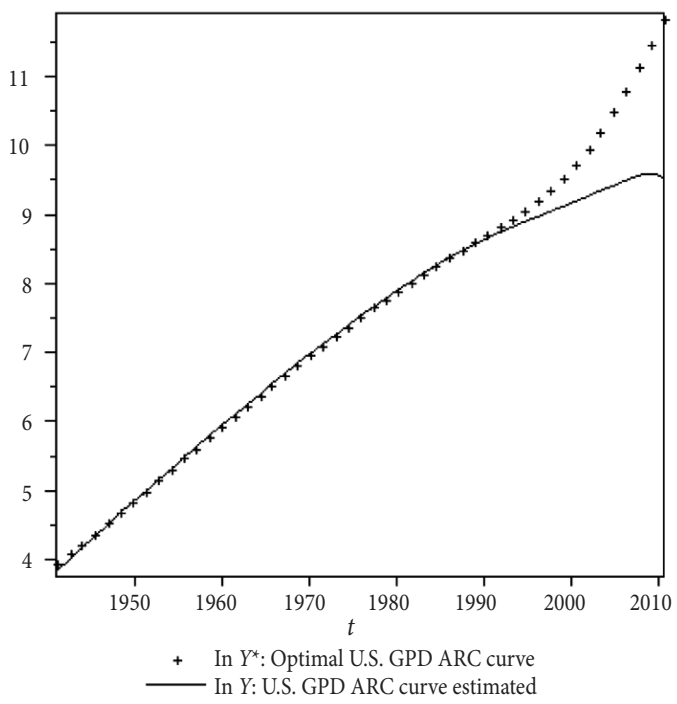

Fig. 2. Comparison of the ARC curve with optimal one for U.S. GDP

Note: The optimal U.S. GDP ARC curve is depicted based on Model (9), and the original U.S. GDP ARC curve is based on Model (6). Both curves are plotted on a logarithmic scale here. We see that the optimal ARC curve agrees with the original ARC curve between 1940 and 1990. After 1990, the optimal ARC curve growth is sustained over time, whereas the original ARC curve declines towards the end.

Fig. 2 compares Model (9) with the Model (6)-based U.S. GDP fitting curves in Fig. 1.

Fig. 2 shows that the optimal ARC curve growth is sustained after 1990, whereas the original ARC curve declines towards the end. Therefore, the optimal industry segmentation promotes output growth under environmental pressure.

\subsection{The empirical analysis of industrial segmentation}

Based on Equation (8) and the data estimated above, the optimal numbers of leading industries for U.S. economy can be computed for each year. The optimal number curves are depicted in Fig. 3 when the competitive advantages are $\beta=0.01, \beta=0.02$, and $\beta=0.05$, respectively. Some computed data are listed in Table 1.

Table 1. The optimal number of industries in the U.S. economy

\begin{tabular}{cccccccc}
\hline \multirow{2}{*}{$\begin{array}{c}\text { Optimal number } \\
\text { of industries: } m^{*}\end{array}$} & $\mathbf{2 0 1 2}$ & $\mathbf{2 0 1 3}$ & $\mathbf{2 0 1 4}$ & $\mathbf{2 0 1 5}$ & $\mathbf{2 0 1 6}$ & \multirow{2}{*}{$\begin{array}{c}\text { Critical } \\
\text { value: } \bar{m}^{*}\end{array}$} \\
\cline { 2 - 7 } & $\beta=0.01$ & 1188.59 & 1217.82 & 1247.05 & 1276.28 & 1305.50 & 763.84 \\
\cline { 2 - 7 } $\begin{array}{c}\text { Competitive } \\
\text { advantage }\end{array}$ & $\beta=0.02$ & 594.29 & 608.91 & 623.52 & 638.14 & 652.75 & 341.70 \\
\cline { 2 - 7 } & $\beta=0.05$ & 237.72 & 243.56 & 249.41 & 255.26 & 261.10 & 114.88 \\
\hline Competitive type: $m^{*} \beta$ & 11.89 & 12.18 & 12.47 & 13.76 & 13.06 & \\
\hline
\end{tabular}

Note: Table 1 shows that the optimal number of industries is smaller if the competitive advantage is greater and that there is an incomplete competition among the industries because $1<m^{*} \beta<m^{*}$. The critical values are computed according to Equation (B.2). 


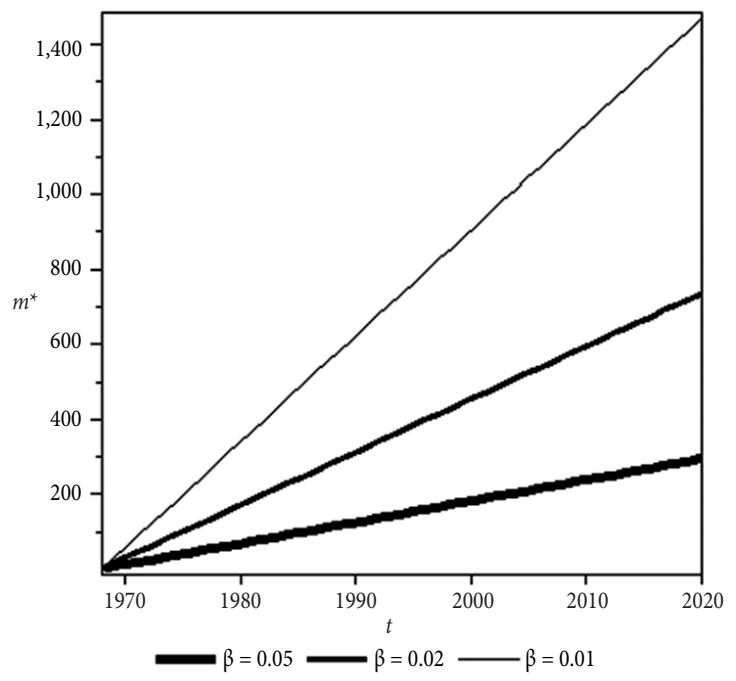

Fig. 3. Optimal number of industries in the U.S. economy from 1968 to 2020

Note: Figure 3 is depicted based on Equation (8) and indicates that the optimal number of industries continues to increases over time. As the competitive advantage increases from 0.01 to 0.05 , the optimal number of industries decreases gradually.

Fig. 3 shows that industry segmentation occured in the late 1960s. As the speed of computers increased dramatically in the late 1960s, technological progress and innovative growth based on computers required and caused industry segmentation. Furthermore, industry segmentation is a fundamental way of changing the economic structure and developing economy.

Table 1 indicates that, there is incomplete competition among the industries and that the optimal number of leading industries increases as the competitive advantage decreases. All the optimal numbers are larger than the critical value for the given competitive advantage, which means that industry segmentation based on the optimal number will promote economic growth.

From Table 1, if $\beta=0.01$, the optimal number of leading industries is $m^{*}(2012)=1188.59$ at time $t=2012$. Therefore, in 2012, it will be most favorable to break down the U.S. economy into approximately 1244 leading industries. This conclusion can be used by the U.S. government and economic authorities to create better economic policies. Currently, the U.S. appears to have no clear statistics regarding their number of leading industries, which means that the U.S. can perform far better industrial planning than it currently does.

\section{Summary and conclusions}

The economy is composed of many industries, and the number of industries in an economy is always changing. What number is most favorable for economic growth? What trends do the changes in this number follow? To address these questions, following investigations are performed based on the Solow growth model and ARC model:

- Build a combinatorial ARC model. Based on an analysis of the growth relation between the integrated basic output, innovation, and environmental pressure, the combinatorial 
ARC model is presented. This model can describe large-scale economic growth under environmental pressure;

- Describe the competition relations between economic entities. Based on the EPI of an economic group, four competition relationships between economic entities are generally described: mutual benefit, non-competition, incomplete competition, and complete competition;

- Compute the optimal number of segmented industries. Under complete competition or incomplete competition, the approach for computing the optimal number of industries in an economy is given, and the real maximum output after optimal industry segmentation is described.

Based on the works above, the following important conclusions are reached:

1) There is an optimal number of leading industries in an economy. Based on the combinatorial ARC model, the optimal number of leading industries for an economy can be computed. If the number of leading industries in an economy is equal to the optimal one, then the real output of the economy reaches its maximum value;

2) Technological progress and innovative growth will promote industry segmentation. The technological progress and innovative growth will require and cause industry segmentation. Furthermore, industry segmentation is a fundamental way of changing the economic structure and developing economy;

3) Industry segmentation will promote economic output growth. Based on ARC analysis, a critical value for industry segmentation can be obtained. If the real number of leading industries is larger than the critical value, then the industry segmentation will increase the real output of the economy.

The most important conclusion in this paper is that the main approach to changing economic structure is through industry and market segmentation. The results are valuable to authorities for deciding and controlling the number of leading industries. If using Model (6) to describe the output growth of a firm that produces many products, we may analyse product diversification in the same way as segmentation in this paper. Conversely, the discussion of market globalization is similar to that of transnational mergers and acquisitions in that the latter may lead to the former, and mergers and acquisitions are the inverse problems of industry segmentation. If using Model (6) to describe the output of an industry and the industry includes many firms, we may discuss mergers and acquisitions in a corresponding way, which will be presented in another paper.

In addition, Models (2) and (6) also apply to developing countries because economic output in developing countries also grows or declines and the growth cannot be unlimited; a growth cycle of any developing countries usually includes four phases: slow growth, rapid growth, stagnation and decline, and Models (2) and (6) may describe the four phases.

\section{References}

Allen, L.; Jagtiani, J. 1997. Risk and market segmentation in financial intermediaries' returns, Journal of Financial Services Research 12(2): 159-173. http://dx.doi.org/10.1023/A:1007974719557

Barro, R. J.; Sala-i-Martin, X. 1995. Economic growth. McGraw Hill: New York. 539 p. 
Battisti, G.; Pietrobelli, C. 2000. Intra-industry gaps in technology and investments in technological capabilities: firm-level evidence from Chile, International Review of Applied Economics 14(2): 253-269. http://dx.doi.org/10.1080/02692170050024778

Boffa, F.; Panzar, J. 2012. Bottleneck co-ownership as a regulatory alternative, Journal of Regulatory Economics 41(2): 201-215. http://dx.doi.org/10.1007/s11149-011-9157-0

Brandt, L.; Thun, E. 2011. Going mobile in China: shifting value chains and upgrading in the mobile telecom sector, International Journal of Technological Learning, Innovation and Development 4(1): 148-180.

Chen, J.; Bell, P. C. 2012. Implementing market segmentation using full-refund and no-refund customer returns policies in a dual-channel supply chain struct, International Journal of Production Economics 136(1): 56-66. http://dx.doi.org/10.1016/j.ijpe.2011.09.009

Choi, H. S. 2013. Money and risk of loss in an asset market segmentation model, International Review of Economics \& Finance 25(C): 146-155. http://dx.doi.org/10.1016/j.iref.2012.07.001

Clark, D. 2006. Country and industry-level determinants of vertical specialization-based trade, International Economic Journal 20(2): 211-225. http://dx.doi.org/10.1080/10168730600699515

Corrocher, N.; Zirulia, L. 2010. Demand and innovation in services: the case of mobile communications, Research Policy 39(7): 945-955. http://dx.doi.org/10.1016/j.respol.2010.04.008

Dai, F.; Liang, L.; Wu, S. 2013. Money supply and economic growth under environmental pressure: the strategy for re-growth, International Journal of Monetary Economics and Finance 6(1): 55-80. http://dx.doi.org/10.1504/IJMEF.2013.055717

Dai, F.; Qi, J. P.; Liang, L. 2011. Socio-economic development model based on stochastic advance-retreat course: an analysis on US economy in recent 70 years, International Journal of Social Economics 38(5): 416-437. http://dx.doi.org/10.1108/03068291111123129

Degryse, H.; Ongena, S. 2004. Bank orientation and industry specialization, in Proceedings of Federal Reserve Bank of Chicago, May, 412-427.

Gluschenko, K. 2010. Anatomy of Russia's market segmentation, Economics of Transition 18(1): 27-58. http://dx.doi.org/10.1111/j.1468-0351.2009.00363.x

He, X. 2009. Corporate diversification and firm value: evidence from post-1997 data-super, International Review of Finance 9(4): 359-385. http://dx.doi.org/10.1111/j.1468-2443.2009.01096.x

Hoffmann, S.; Soyez, K. 2010. A cognitive model to predict domain-specific consumer innovativeness, Journal of Business Research 63(7): 778-785. http://dx.doi.org/10.1016/j.jbusres.2009.06.007

Kesting, T.; Rennhak, C. 2011. Market segmentation in German business practice: relevance, procedures and challenges, World Review of Entrepreneurship, Management and Sustainable Development 7(4): 361-379. http://dx.doi.org/10.1504/WREMSD.2011.042891

Ko, E.; Taylor, C. R.; Sung, H.; Lee, J.; Wagner, U. 2012. Global marketing segmentation usefulness in the sportswear industry, Journal of Business Research 65(11): 1565-1575.

http://dx.doi.org/10.1016/j.jbusres.2011.02.041

Leuvenstei, M. V.; Bikker, J.; Rixtel, A. V.; Srensen, C. K. 2011. A new approach to measuring competition in the loan markets of the euro area, Applied Economics 43(23): 3155-3167. http://dx.doi.org/10.1080/00036840903493234

Liu, Y.; Ram, S.; Lusch, R. F.; Brusco, M. 2010. Multicriterion market segmentation: a new model, implementation, and evaluation, Marketing Science 29(5): 880-894.

http://dx.doi.org/10.1287/mksc.1100.0565

Menzly, L.; Ozbas, O. 2010. Market segmentation and cross-predictability of returns, The Journal of Finance 65(4): 1555-1580. http://dx.doi.org/10.1111/j.1540-6261.2010.01578.x

Mitchell, K.; McDade, M. D. 1992. Preferred habitat, taxable/tax-exempt yield spreads, and cycles in property/liability insurance, Journal of Money, Credit and Banking 24(4): 528-552.

http://dx.doi.org/10.2307/1992810 
$\mathrm{Mu}, \mathrm{Q}$.; Lee, K. 2005. Knowledge diffusion, market segmentation and technological catch-up: the case of the telecommunication industry in China, Research Policy 34(6): 759-783. http://dx.doi.org/10.1016/j.respol.2005.02.007

Pupillo, L.; Zimmermann, K. 1991. Relative export prices and firm size in imperfect markets, Open Economies Review 2(3): 295-304. http://dx.doi.org/10.1007/BF01886147

Reed, W. 2001. The Pareto Zpif and other power law, Economics Letters 74(1): 15-19. http://dx.doi.org/10.1016/S0165-1765(01)00524-9

Ruiz de Ma, S.; López, I.; Munuera, J. L. 2011. Organic food consumption in Europe: international segmentation based on value system differences, Ecological Economics 70(10): 1767-1775. http://dx.doi.org/10.1016/j.ecolecon.2011.04.019

Sanchez, J. R.; Gonzalez-Estevez, J.; Lopez-Ruiz, R.; Cosenza, M. G. 2007. A model of coupled maps with Pareto behavior [online], [cited 6 June 2013]. Available from Internet: http://arxiv.org/pdf/ nlin/0701016.pdf

Schoenberg, F. P.; Peng, R.; Woods, J. 2003. On the distribution of wildfire sizes, Environmetrics 14(4): 583-592. http://dx.doi.org/10.1002/env.605

Shapiro, D.; Shi, X.W. 2008. Market segmentation: the role of opaque travel agencies, Journal of Economics \& Management Strategy 17(4): 803-837. http://dx.doi.org/10.1111/j.1530-9134.2008.00196.x

Solow, R. M. 1956. A contribution to the theory of economic growth, Quarterly Journal of Economics 70(1): 65-94. http://dx.doi.org/10.2307/1884513

Solow, R. M. 1957. Technical change and the aggregate production function, Review of Economics and Statistics 39(3): 312-320. http://dx.doi.org/10.2307/1926047

Zhang, L.; Wu, Y. 2012. Market segmentation and willingness to pay for green electricity among urban residents in China: the case of Jiangsu Province, Energy Policy 51(3): 514-523.

http://dx.doi.org/10.1016/j.enpol.2012.08.053

\section{APPENDIX A}

There is an optimal number of industries in an economy, and the optimal number increases with technological progress and innovative growth. This proposition can be proved below:

Based on Model (7), the real output of an economy is the sum of real outputs of $m$ industries, that is:

$$
m \cdot Y_{m}=\Gamma-\Phi+U-m\left(\frac{w}{\theta} U^{\theta}\right)^{\frac{1}{m \beta}} .
$$

According to Models (6) and (A.1), the difference between the real outputs of economy before and after industry segmentation is as follows:

$$
\Delta=m \cdot Y_{m}-Y=\frac{w}{\theta} U^{\theta}-m \cdot\left(\frac{w}{\theta} U^{\theta}\right)^{\frac{1}{m \beta}}
$$


Let $\frac{d \Delta}{d m}=\left(\frac{w}{\theta} U^{\theta}\right)^{\frac{1}{m \beta}}\left[\frac{1}{m \beta} \ln \left(\frac{w}{\theta} U^{\theta}\right)-1\right]=0$; we obtain the optimal number of industries in an economy as follows:

$$
m^{*}=\frac{1}{\beta} \ln \left(\frac{w}{\theta} U^{\theta}\right),
$$

where: $m^{*}>1$, that is, $U>\left(\frac{\theta}{w} e^{\beta}\right)^{1 / \theta}$.

Under Equation (A.3), $\frac{d \Delta}{d m}=0$ and $\frac{d^{2} \Delta}{d m^{2}}=-\frac{1}{m^{2} \beta} \ln \left(\frac{w}{\theta} U^{\theta}\right)<0$. In this case, Equation (A.2), i.e. the difference between the real outputs of economy before and after industry segmentation, reaches its maximum. None of $w, \theta, \beta$, or $U$ vary with $m$, and $\frac{1}{m^{*} \beta} \ln \left(\frac{w}{\theta} U^{\theta}\right)-1=0$, so $\frac{1}{m^{\prime} \beta} \ln \left(\frac{w}{\theta} U^{\theta}\right)-1<0$ for any $m^{\prime}>m^{*}$ and $\frac{1}{m^{\prime} \beta} \ln \left(\frac{w}{\theta} U^{\theta}\right)-1>0$ for any $m^{\prime}<m^{*}$. Therefore, Equation (A.3) is the only maximum of Equation (A.2).

Because the emerging output $U=G \cdot Q$ in Model (6), where $Q$ is the innovation, Equation (A.3) indicates that the innovative growth will increase the optimal number. Therefore, technological progress and innovative growth will promote industry and market segmentation.

Substituting Equation (A.3) into Model (A.1), we have the real maximum output after industry segmentation as follows:

$$
Y^{*}=m^{*} \cdot Y_{m^{*}}=\Gamma-\Phi+U-\frac{e}{\beta} \ln \left(\frac{w}{\theta} U^{\theta}\right) .
$$

\section{APPENDIX B}

There is a critical value for industry segmentation, which is determined by $\bar{m}^{*}=\frac{1}{\beta}\left(1+\ln \bar{m}^{*}\right)$. If the real number of leading industries is larger than the critical value, then the industry segmentation will increase the real output of an economy. This proposition is proven below:

Substituting Equation (A.3) in Appendix A into Equation (A.2), the maximum difference between the real outputs of economy before and after industry segmentation is as follows:

$$
\Delta^{*}=e^{m^{*} \beta}-m^{*} \cdot e .
$$

When $\Delta^{*}=0$, we have:

$$
m^{*}=f\left(m^{*}\right)=\frac{1}{\beta}\left(1+\ln m^{*}\right) .
$$

According to Equation (B.2), we have $f^{\prime}(m)=\frac{1}{\beta \cdot m}$. Then:

(1) Under incomplete competition, we have $1<\beta m<m$, i.e. $\left|f^{\prime}(m)\right|=f^{\prime}(m)=\frac{1}{\beta \cdot m}<1$. In this case, there is a fixed point $m_{1}^{*}$ for Equation (B.1), and $m_{1}^{*}=\frac{1}{\beta}\left(1+\ln m_{1}^{*}\right)$;

(2) Under complete competition, $\beta^{*} \geq 1$ and the number of industries is greater than one, i.e. $m^{*}>1$; therefore, $\left|f^{\prime}(m)\right|=f^{\prime}(m)=\frac{1}{\beta \cdot m}<1$. In this case, there is a fixed point $m_{2}^{*}$ for Equation (B.1), and $m_{2}^{*}=\frac{1}{\beta}\left(1+\ln m_{2}^{*}\right)$. 
According to the above analysis, there is a fixed point for Equation (B.2) under incomplete and complete competition, and the fixed point is related to the competitive advantage. We know from Equation (B.2) that $f^{\prime}(m)=\frac{1}{\beta \cdot m}>0$ and $f(m)=\frac{1}{\beta}(1+\ln m)$ is an increasing function. When the real number of leading industries is larger than the fixed point, the maximum difference between the real outputs of an economy after and before industry segmentation is greater than zero, i.e. $\Delta^{*}>0$; therefore, the industry segmentation will increase the real output of the economy. In this case, the more leading industries exist, the higher the real output of the economy. Thus, the fixed point is a critical value.

Feng DAI is a Professor of Economic Management and Science at Department of Management Science, Zhengzhou Information Engineering University (China). His publications include nine books and more than 60 articles in renowned international journals/conferences. He is a Director of Management Science Society in China and is a Member of IAES.

Jingxu LIU is a Dr and works at the Department of Management Science, Zhengzhou Information Engineering University (China). Her publications include two books and more than 10 articles.

Ling LIANG is an Associate Professor at Department of Management Science, Zhengzhou Information Engineering University (China). Her publications include two books and more than 30 articles. 